\title{
NARRATIVAS SOBRE O PATRIMÔNIO INDUSTRIAL: FERRAMENTARIAS DE MOLDES E MATRIZES EM JOINVILLE/SC
}

\author{
Narratives on the Industrial Heritage: toolmakers of \\ molds and dies in Joinville / SC
}

Christiane Heloisa Kalb*

Mariluci Neis Carelli**

\begin{abstract}
RESUMO
Este artigo analisa a importância do patrimônio industrial, especialmente no que se refere às ferramentarias de moldes e matrizes para a cidade de Joinville/SC. A cidade é conhecida internacionalmente por seu potencial industrial, principalmente na área de ferramentarias. Contudo essa realidade já conta com algumas décadas de história que pode ser contada a partir das memórias dos primeiros ferramenteiros, que iniciaram suas atividades durante a década de 1980. A metodologia utilizada foi embasada em revisão bibliográfica e na análise das entrevistas orais obtidos pelo Projeto de Pesquisa nominado Patrimônio Industrial de Joinville - PIJ. Durante a pesquisa ficou claro a ligação entre a identidade dos entrevistados, em sua maioria empresários ativos ou já aposentados, com a chamada cidade industrial de Joinville, por esse motivo, merecedora de estudos mais aprofundados sobre o patrimônio cultural industrial em seus aspectos materiais e imateriais, a partir das memórias desses empresários.
\end{abstract}

Palavras-chave: Patrimônio Industrial, Ferramentarias, Memórias.

\footnotetext{
${ }^{*}$ Doutoranda em Ciência Humanas, pela Universidade Federal de Santa Catarina UFSC, Mestre em Patrimônio Cultural e Sociedade, pela Univille; Especialista em Processo civil e Direito Civil. Atua como advogada em Santa Catarina.

** Mestre em Sociologia Política pela Universidade Federal de Santa Catarina (1992) e Doutora em Engenharia da Produção pela Universidade Federal de Santa Catarina (2004).
} 


\begin{abstract}
Thisarticle looks attheimportanceof industrial heritage, especiallywithregardtotoolingof dies andmolds for the city of Joinville / SC. The city isinternationallyknown for its industrial potential, especially in thetoolingarea. Howeverthis reality alreadyhasseveraldecadesofhistorythatcanbetoldfromthe memories oftheearlytoolmakers, whichbeganoperationsduringthedecadeof 1980. The methodologyusedwasbasedonliteraturereviewandanalysisof oral interviews obtainedbythe Project Researchnamed Industrial Heritage Joinville - PIJ. Duringtheresearch it becameclearthe link betweentheidentityofrespondents, mostlyactiveoralreadyretiredentrepreneurs, withtheso-called industrial city of Joinville, therefore, worthyoffurtherstudyonthe industrial cultural heritage in its material andimmaterialaspects, fromthe memories oftheseentrepreneurs.
\end{abstract}

Keywords: Industrial Heritage, Toolmakers, Memories. 


\title{
Introdução
}

O estudo do patrimônio industrial, no que se refere ao patrimônio de Joinville, possui diversas problemáticas que dificultam um diagnóstico mais preciso e completo.Pode-se observar que não só as edificações e os vestígios materiais são alvos da falta de preservação e,por conseguinte, conservação por parte das autoridades competentes e da própria sociedade, mas também os vestígios imateriais têm se perdido com o passar do tempo. Isso ocorre pela ausência de interesse em pesquisas na área e de registros propriamente ditos.

As formulações teóricas que se iniciaram na década de 1950, a partir das consequências da Segunda Guerra Mundial, principalmente na Inglaterra não se verificam concretamente no campo prático, pelo menos no âmbito brasileiro e, por conseguinte joinvilense, o que dificulta ainda mais os meios de proteção destes bens culturais de origem industrial, que muitas vezes se transformam em gigantes "elefantes brancos" sem uma utilização adequada, ou ainda sendo utilizados sem critérios e sem a verificação de sua referência histórico-social.

\section{De acordo com a Carta de NizhnyTagil $1^{1}$}

\begin{abstract}
o patrimônio industrial compreende os vestígios da cultura industrial que possuem valor histórico, tecnológico, social, arquitetônico ou científico. Estes vestígios englobam edifícios e maquinaria, oficinas, fábricas, minas e locais de processamento e de refinação, entrepostos e armazéns, centros de produção, transmissão e utilização de energia, meios de transporte e todas as suas estruturas e infraestruturas, assim como os locais onde se desenvolveram atividades sociais relacionadas com a indústria, tais como habitações, locais de culto ou de educação
\end{abstract}

1 Em julho de 2003, na cidade russa deNizhnyTagil, a Comissão Internacional para a Conservação do Patrimônio Industrial (TICCIH) reuniu-se para discutir o tema. Desse encontro surgiu a Carta de NizhnyTagil. Conforme bem expuseram PAVANELLO, L.; GUEDES, S. Um novo olhar sobre o patrimônio comercial: os secos e molhados em Joinville. Rev História: Questões e Debates, Curitiba, n 59, pp. 241-261, jul/dez 2013. Edit UFPR. p. 245. 
Na cidade de Joinville, um dos exemplares industriais que é protegido pelo IPHAN é a Companhia Wetzel, tombada em 2009, que atualmente tem sido utilizada pela Universidade Católica de Santa Catarina. E ainda existem o Moinho de Farinha Santista e a Cervejaria Antarctica - Cidadela Cultural, também tombados ${ }^{2}$.

No entanto, ameaças ao patrimônio existem constantemente, principalmente com o crescimento das cidades e a pressão especulatória imobiliária, sendo assim os valores culturais deixam de ser reconhecidos e há constantes investidas deformadoras e desinformadas, que chegam a destruir os bens imóveis comprometendo seu valor cultural-industrial.

Isso vem ocorrendo tanto nas obras de valor artístico, como por outro lado, em obras de interesse/valor histórico. O mesmo ocorre com as fábricas e as empresas de porte industrial de Joinville, que com o passar dos anos são deslocadas das áreas centrais para os parques fabris e nem sempre tem seu parque fabril preservado, por falta de interesse público e/ou privado.

Grande parte das ferramentarias ainda em funcionamento na cidade está localizada na Avenida Santos Dumont e suas adjacências. Porém acredita-se que muitas destas empresas iniciaram as suas atividades em outras localidades, i.e., em "fundos de quintal", que hoje já se perderam na história, permanecendo apenas na memória de seus fundadores. Por serem empresas relativamente recentes, datam em média de 1980, se comparadas com outros exemplares industriais como a Serraria do Príncipe, datada de 1856, não há nenhuma ferramentaria tombada por lei na cidade, nem sítios históricos registrados.

Como guardar toda esta memória, parte de nossa identidade? Já que o patrimônio material praticamente se perdeu.

2 Site da Prefeitura de Joinville. Disponível em: < http://www.joinvillecultural.sc.gov. br/site/downloads/Patrimonio_Bens\%20Tombados.pdf $>$ Acesso em: 09 out 2012. 
O mundo moderno produz traços e imagens a um nível jamais visto na história das sociedades humanas, estando em parte submisso às ideologias de segurança da história e da memória que conduzem a tudo conservar, tudo armazenar, musealizar a totalidade do mundo conhecido e, por outro lado, continuando a produzir mais informações e mensagens ${ }^{3}$.

O objetivo desse artigo, então, é analisar as memórias sobre a origem e a formação das primeiras ferramentarias em Joinville, a partir de meados da década de 1980, empresas, em sua maioria, descendentes de grandes empresas. E tais memórias já estão sendo conservadas por meio do Núcleo de Usinagem e Ferramentaria da ACIJ - Associação Empresarial de Joinville, bem como, disseminada por meio da publicação de um livro que trata desse tema.

\section{O Patrimônio industrial a partir dos estudos memorísticos}

As ferramentarias de Joinville surgiram em sua maioria em decorrência da desverticalização do mercado. As grandes empresas da cidade que desde a sua constituição produzia todos os componentes de seus produtos finais, por exemplo, uma geladeira completa, após a desverticalização, terceirizou muitas partes do processo de produção. Assim, consequentemente, muitas pessoas foram dispensadas de seus empregos, o que gerou uma bolha de desemprego na cidade no fim de década de 1970, início de 1980.

Contudo, nem todos desistiram. Muitos trabalhadores se uniram com vizinhos, ex-colegas de trabalho, parentes, que detinham o conhecimento técnico para trabalhar e criaram as primeiras empresas, muitas vezes inicialmente no "fundo dos quintais", que vendiam esses serviços e produtos terceirizados para as grandes empresas, na qual haviam sido dispensados.

3 CANDAU, Joël. Memória e identidade. (trad) Maria Leticia Ferreira. São Paulo: Contexto, 2011. p. 113. 
Essas empresas foram crescendo e se especializando, até que foi necessário um aprimoramento técnico, que inicialmente era feito pela busca de mão de obra especializada no exterior, muitas das vezes, na Alemanha, país que trouxe vários imigrantes para Joinville, desde a fundação em 1851 até meados da Segunda Guerra. Contudo, não só europeus qualificados eram trazidos para a cidade, mas também os proprietários das indústrias e seus filhos (as) eram para lá enviados, para aprender o modo de fabricar, inventar, inovar nos cursos e estágios nas empresas europeias, principalmente alemãs.

Em pesquisa realizada por MuhamadBakkar ${ }^{4}$, para sua dissertação de mestrado em economia, em 2009, Joinville já concentrava naquele ano, mais de cem ferramentarias de diversos portes e capacidades, atuando no segmento específico de moldes plásticos de até 10 toneladas, com a média de 20 funcionários em cada empresa. Apesar de estar vinculado a um mercado bastante diversificado, tanto regional, como nacional, esse pólo industrial tornou-se bastante conhecido pela sua excelência no atendimento aos moldes da construção civil, linha branca e autopeças, sendo considerado o $2^{\circ}$ maior pólo industrial brasileiro, no que se concernem às fundições. Pesquisa científica que está totalmente alinhada com as memórias dos ferramenteiros.

A memória quando trabalhada com uma lógica de tempo se interpenetra de situações fundamentais para reconstruir o passado de determinadas pessoas, que possuam algo em comum. No caso dos ferramenteiros de Joinville a reconstrução do passado ocorre por meio da análise do início das primeiras empresas propriamente ferramenteiras, dos percalços e dos sucessos alcançados durante o período de constituições e manutenção dessas empresas.Lembrando que após um certo período de sucesso, hoje essa profissão vem passando por uma

4 BAKKAR, Muhamad. A indústria eletrometal-mecânica da região de Joinville: do aglomerado industrial ao arranjo produtivo local. 2009, 105 f. dissertação (Mestrado em economia). UFPR - Universidade Federal do Paraná, Curitiba.p. 46. 
modificação, se comparada aos moldes da década de 1980 e 1990. A profissão de ferramenteiroestá se reinventando. Está havendo uma verdadeira renovação e porque não dizer, remodelação desta profissão.

A ferramentaria, por ser do ramo da metalurgia, desenvolve e produz ferramentas e peças, a partir de instrumentos de precisão, ou seja, precisa dispor de profissionais habilidosos, que detenham a capacidade de visão em $3 D$ quando o produto está sendo criado. $\mathrm{Ou}$ seja, pessoas que consigam visualizar um produto final com profundidade e perspectiva (3D) num papel/projeto plano que possui apenas duas dimensões, altura e profundidade $(\mathrm{x} / \mathrm{y}-2 \mathrm{D})$.

Percebe-se que com a tecnologia e a inovação dos últimos anos, os profissionais não precisam mais deste olhar, deixam de pensar o 3D, já que a ideia surge e lhe é aplicada no programa de computador, que cria o produto final já com profundidade e perspectiva. A criatividade perde espaço para a tecnologia. E a profissão de ferramenteiro se reinventa.

Assim, "os processos de terceirização e de informatização industrial são algumas das principais características que se pode destacar para apontar rumos e tendências futuras para a ferramentaria"s. Cada profissional reduzirá cada dia mais os papéis e projetos planos, para utilizar cotidianamente os computadores de alta tecnologia de visão tridimensional, embora as virtudes do ferramenteiro sempre serão necessárias para a continuidade bem sucedida deste setor. "A visão e o tato, sob comando das mãos e da inteligência, ainda serão responsáveis pelos ajustes mais finos, mesmo que essas atividades cobrem em postos de trabalho sua nobreza"'. Visualiza-se nesta afirmação o patrimônio industrial imaterial representado nas ferramentarias da cidade.

5 SENAI. DN. A família ocupacional de ferramenteiros e afins. Brasília, 2002. 76 p, p. 73.

6 Ibidem, p. 74. 
O processo de constituição das ferramentarias na cidade de Joinville é ponto chave para se compreender a industrialização de um modo geral, assim como o inverso também é verdadeiro. Este setor continua crescendo e se destacando nos meios industriais, o que motiva ainda mais os empresários da cidade a investir em seus empreendimentos e consequentemente em Joinville.

Percebe-se que o patrimônio industrial voltado às ferramentarias na cidade se tornou há muito tempo o patrimônio cultural deste lugar. Neste contexto, o que se constitui patrimônio para Claudia Carvalho ${ }^{7}$, é uma noção que envolve, em primeiro lugar, um conjunto de posses que cumpre identificar como transmissíveis, como ocorre na questão da cultura industrial da cidade, é importante observar quealguns jovens têm como sonho de trabalho, seguir os passos de seus pais, na qual sempre trabalharam no âmbito fabril, fundindo e torneando peças, criando moldes e matrizes. Em seguida, um grupo humano, uma sociedade, capaz ou suscetível de reconhecê-las como suas, de demonstrar a sua coerência e de organizar a sua recepção, como também ocorre em Joinville, cidade conhecida até mesmo internacionalmente por ser um pólo industrial de fundição. Sendo reconhecida a cidade por este patrimônio industrial, pressupõe-se que o seu povo, que convive cotidianamente neste setor, neste estilo de vida voltado ao trabalho e à criatividade também reconhecem na cidade o seu patrimônio. Por fim, mas não menos importante, que possua um conjunto de valores, políticos no sentido mais geral do termo, que permita articular os legados do passado à espera ou à configuração de um futuro, como o objetivo de promover algumas mutações e, ao mesmo tempo, afirmar uma continuidade. Fato que ocorre todos os dias na cidade, contudo não só nos bairros onde estão as fábricas predominantemente, mas isso se sente no centro, onde

\footnotetext{
7 CARVALHO, Claudia S. Rodrigues, et al. Um olhar contemporâneo sobre a preservação do patrimônio cultural material. Rio de Janeiro: Museu Histórico Nacional, 2008.p.36.
} 
o sentimento industrial pulsa pelo trabalho e por buscar uma vida melhor e mais confortável para a família e para o indivíduo em si.

\section{Joinville e seu patrimônio industrial ferramenteiro}

O processo de colonização europeu (de língua alemã, tradição germânica e religião protestante, em sua maioria) em meados do século XIX na cidade de Joinville foi uma das grandes causas da formação do aglomerado eletro-metal-mecânico, composto por inúmeras pequenas atividades mercantis e manufatureiras, bem como de ferramentarias, observa-se que ambas se entrelaçam durante os processos de produção industrial.

Cabe neste momento esclarecer, ainda que brevemente o processo de constituição do setor de ferramentaria ${ }^{8}$ de Moldes e Matrizes.As ferramentarias de moldessurgiram a partir da ampliação da indústria do vidro, em 1769, quando o Marquês de Pombal autorizou Guilherme e Diogo Stephens (ingleses) a abrir uma fábrica de vidros na Marinha Grande (cidade portuguesa no distrito de Leiria, região Centro e sub-região do Pinhal Litoral). Obviamente que os portugueses não foram os primeiros na criação dos moldes em si, cita-se o inglês Henry Maudslay que aperfeiçoou o torno mecânico e desenvolveu as máquinas ferramenta. Mas, Portugal é conhecido pela sua origem e tecnologia vidreira até mesmo atualmente. Imagina-se que outros profissionais, de outros países como por exemplo a Alemanha,também já conheciam as técnicas de moldes com outros mecanismos, como por meio do ferro ou da madeira, como fizeram os imigrantes europeus que chegaram a Joinville.

8 O conceito de ferramenta: é um utensílio de ferro de trabalhador, ou utensílio de uma arte ou ofício. Já o ferramenteiro é um mecânico especializado na confecção de ferramentas e moldes. Conforme: FERREIRA, Aurélio Buarque de Holanda, Novo Aurélio século XXI: o dicionário da língua portuguesa. 3. ed. Rio de Janeiro: Nova Fronteira,1999, p. 402. 
Assim, Beltrão ainda menciona que Portugal "foi a pré-história dos moldes em que as boas vontades, a arte, a sensibilidade e o desejo de vencer tudo, souberam superar e levar de vencida, criando-se um escol de operários especializados e, fundamentalmente, interessados e orgulhosos da sua indústria"9 o que coaduna com os acontecimentos ocorridos nas primeiras ferramentarias na cidade de Joinville.

Especificamente sobre as ferramentarias que trabalham com moldes e matrizes para fabricação de plástico, é importante pontuar que esse material está presente no cotidiano de muitas pessoas em todo o mundo, sob diversas formas. Desde a sua criação, a sua utilização cresceu consideravelmente, substituindo materiais como aço, madeira, ferro e vidro em diversas situações diárias. Com certeza, o material plástico tornou-se objeto de estudo dos profissionais da área de ferramentaria, no que concerne aos moldes dos produtos que inicialmente eram feitos de ferro ou de madeira, quase que manualmente, hoje por meio de sistemas de injeção, sopro e extrusão, em máquinas que trabalham praticamente sozinhas. Este saber pertencente aos antigos ferramenteiros tornou-se um patrimônio industrial imaterial nas empresas que atuam e atuaram neste setor, uma vez que este material (plástico) hoje moldado por máquinas, como dito anteriormente, eram feitos pelas mãos dos profissionais e merece ser preservado.

Vale lembrar que além da área de atuação plástica, ou seja, de moldes para termoplásticos, os ferramenteiros também atuam em outras áreas, como de corte, dobra e repuxo; de dispositivos e; de modelação de metais (para fundição), somando as 4 principais áreas de atividade ${ }^{10}$, que abrangem a metalurgia, dispositivos e plásticos.

\footnotetext{
9 A INDÚSTRIA de moldes e plásticos. Correio de Azemeis. Caderno especial. ed. Valter Santos. Suplemento da edição n. 2777. Portugal. abr e maio, 1981, p. 23.

${ }^{10}$ SENAI, DN, 2002, p. 44.
} 
O sentimento de pertença dos profissionais deste ofício é um patrimônio que não se pode perder. Ainda que os novos ferramenteiros mal saibam como tudo se iniciou, a memória dos criadores precisa ser registrada, pois este conhecimento da "gênese" é algo precioso. Do ponto de vista profissional entender o desenvolvimento de um produto desde o seu início, os procedimentos fabris até o produto final comercializável fazem parte da cultura da cidade, não só de Joinville, mas é importante, sobremaneira, para os profissionais da área e para as futuras gerações.

\section{As memórias dos ferramenteiros}

Antes de discorrer propriamente sobre as memórias, precisamos nos questionar e responder: Toda memória deve ser preservada? Entendemos que não. A memória precisa ter relevância e ser assim avaliada e tratada por alguém que se interesse em preservá-la, da mesma forma que se está aqui a fazer.

A salvaguarda das memórias dos acontecimentos que envolveram os ferramenteiros de Joinville, como meio de se conservar estas informações, "remete-nos em primeiro lugar a um conjunto de funções psíquicas, graças às quais o homem pode atualizar impressões ou informações passadas, ou que ele representa como passadas"11. Além disso, a "história oral explicita que as fontes são pessoas, que ao serem motivadas a narrar, expressam o significado de suas experiências por meio dos fatos" $"$.

11 LE GOFF, Jacques. História e memória. (trad.) Bernardo Leitão. Campinas: Ed. da Unicamp, 2003. p. 419.

12 PORTELLI, Alessandro. A filosofia e os fatos. Tempo, Rio de Janeiro, v. 1, n. 2, p. 59-72, 1996 apudCOELHO, Ilanil.Pelas tramas de uma cidade migrante: Joinville: Editora da Univille, 2011, p. 46. 
Tanto Le Goff como Portelli esclarecem a importância do cuidado na análise das memórias, pois muitas vezes pode haver uma recorrência ou certa repetição de fatos que nem sempre condizem com a "realidade" do que aconteceu.

\title{
Conforme Le Goff ${ }^{13}$ ainda
}

\begin{abstract}
Memória é um fenômeno individual e psíquico, a memória liga-se também à vida social. Esta varia em função da presença ou ausência da escrita e é objeto da atenção do Estado que, para conservar os traços de qualquer acontecimento do passado, produz diversos tipos de documentos - monumentos, faz escrever a história, acumular objetos. A apreensão da memória depende deste modo do ambiente social e político, trata-se da aquisição de regras retóricas e também da posse de imagens e textos de apropriação do tempo. As direções atuais da memória estão, pois, profundamente ligadas às novas técnicas de cálculo, de manipulação de informação, do uso de máquinas e instrumentos, cada vez mais complexos.
\end{abstract}

Em Joinville, desde o início do processo de colonização, em meados do século XIX, os imigrantes sempre viveram os seus dias por meios de crenças e ritualizações de seus imaginários sociais, que tinham por base as lembranças e os fatos empreendedores ocorridos no passado europeu. Essas memórias foram exportadas para a nova vivência na cidade ainda inexplorada, que aos poucos foi crescendo e criando a sua própria identidade. A identidade de Joinville é múltipla e complexa, possuindo diversos aspectos imateriais e diversas identidades. Por isso, é necessário questionar o sucesso absoluto ou o fracasso total na implantação das primeiras ferramentarias independentes.

Estudar, então o Imaginário Social de uma determinada sociedade, e nesse caso, de uma cidade é "dialogar com seu mistério,

${ }^{13}$ LE GOFF, J. Memória. In. História e memória. 2. ed. Campinas: Unicamp, 1992. pp. 423-483 
com suas crenças mais profundas"14, pois é o local onde se "escondem" as representações sociais daquele povo, chamados também de "lugares de memória"15, conforme diz Nora. Afinal, Candau ${ }^{16}$ conclui que não há uma procura de identidade sem memória e da mesma forma uma busca pela memória sempre vem anexa a um sentimento de identidade, ao menos de cada indivíduo. "Identidade é estado, memória, faculdade" $"$.

Entendimento totalmente relacionado com as memórias advindas dos ferramenteiros de Joinville, que traduzem uma das identidades da cidade. Ainda que esta identidade seja construída por uma pequena parcela da sociedade joinvilense, ou seja, seus empresários e lideranças locais, sob os auspícios da denominação de "cidade dotrabalho", neste sentido conforme entende Candau, este entendimento pode ser considerado uma "retórica holista"18, ou seja, uma memória generalizante, excludente de outros entendimentos voltados à cultura, ao lazer, ao esporte ou à educação, que obviamente fazem parte também do cotidiano desta cidade. Mas ainda assim, o autor entende que é totalmente possível haver uma memória coletiva e bastante pertinente dentro de grupos menores, que coadunam mutuamente da mesma memória.

Analisaremosas memórias dos profissionais que atuam ou atuaram na área das ferramentarias, conforme quadro 1, mostrando ainda o nome da empresa onde trabalham (trabalharam), o nome do

${ }^{14}$ Ibidem.

15 NORA, Pierre. Entre história e memória: a problemática dos lugares. Revista Projeto História, São Paulo, v. 10, p. 7-28, 1993. Revista do Programa de Estudos Pós-Graduados em História e do Departamento de História da PUC-SP (Pontifícia Universidade Católica de São Paulo).

16 CANDAU, Joël. op. cit., p. 19.

${ }^{17}$ CANDAU, Joël. op. cit.,p. 21.

${ }^{18}$ Ibidem. 
entrevistado e o ano de fundação destas empresas.

Quadro 1: Nomes dos entrevistados, empresa que pertencem/pertenciam e ano de fundação destas, Joinville, 2012.

\begin{tabular}{|c|c|c|}
\hline Nome da empresa & Ano de fundação & $\begin{array}{l}\text { Nome do } \\
\text { entrevistado }\end{array}$ \\
\hline BTOMEC $^{20}$ & 1985 & $\begin{array}{l}\text { WilardTiergarten } \\
\text { (Rio do Sul) }\end{array}$ \\
\hline TIGRE & 1941 & $\begin{array}{l}\text { Rudolf Hufen (cidade } \\
\text { de Koblenz, Alemanha) }\end{array}$ \\
\hline $\begin{array}{c}\text { AKROS / Fred Jung Moldes e } \\
\text { Matrizes }^{21}\end{array}$ & 1976 / 1989 & $\begin{array}{l}\text { Christian Dhilmann } \\
\text { (Tubarão) }\end{array}$ \\
\hline UDESC / UNIVILLE & 1956 / 1965 & $\begin{array}{c}\text { Carlos Alberto Lessa } \\
\text { (Jaguaruna) }\end{array}$ \\
\hline $\begin{array}{c}\text { TIGRE / AKROS / Fred Jung } \\
\text { Moldes e Matrizes }\end{array}$ & 1941 / 1976 / 1989 & $\begin{array}{c}\text { Ademar Hessen } \\
\text { (Joinville) }\end{array}$ \\
\hline SENAI & 1944 & $\begin{array}{c}\text { Ronaldo Espesim } \\
\text { Francisco (Siderópolis) }\end{array}$ \\
\hline $\begin{array}{c}\text { Oficinas Mecânicas / Ambalit } \\
\text { Ind. Plástico / Tupy / Hansen } \\
\text { Máquinas (Tigre) }\end{array}$ & $\begin{array}{c}1936 \text { (Mário } \\
\text { OsnilGrube Antunes } \\
\text { e Mário Colin) / } 1938 \\
\text { / } 1941\end{array}$ & $\begin{array}{l}\text { Henry Schmalz } \\
\text { (Joinville) }\end{array}$ \\
\hline
\end{tabular}

Fonte: Elaborado por Christiane Kalb, de acordo as entrevistas disponiveis no Projeto de Pesquisa, no Anexo 2, de KALB, C. Patrimônio Industrial: as memórias de ferramenteiros em Joinville [Dissertação de mestrado],Univille, Joinville, 2012. $198 f$.

Os procedimentos baseados em entrevistas são muito antigos, mas ganharam uma maior força nas últimas décadas, também no Brasil. Entretanto, as pesquisas baseadas na história oral apesar de suas potencialidades possuem seus limites, é preciso considerar que a responsabilidade do pesquisador não se dissolva em meio às

${ }^{19}$ BTOMEC Ferramentaria e Usinagem de Precisão Ltda, Sócio de Willard, o Sr. Armando Bohn. Cfe. Site da empresa. Disponível em: $<$ http://www.btomec.com. br>. Acesso em: 12 maio 2012.

${ }^{20}$ Atualmente denominada de Herten Engenharia de Moldes Ltda. 
lembranças dos entrevistados. O resultado almejado neste estudo é justamente o encontro das memórias individuais e coletivas com as bases bibliográficas.

Mais do que para servir a ilustrar afirmações, são usadas para compor quadros demonstrativos de trajetórias profissionais, a partir da vivência de trabalhadores que, apesar de sua individualidade, tem em comum a profissão que os aproxima e associa numa espécie de comunidade de destino, o que também os assemelha. ${ }^{21}$

Ressalta-se que as entrevistas estão disponíveis e foram disponibilizadas pelo projeto de pesquisa (PIJ) que também tem como um dos resultados, além de uma dissertação defendida em 2012, a realização de um documentário, já gravado e de um livro que foi publicado em agosto de 2014.

Assim, deve-se ressaltar que a especialização metalomecânica da indústria local foi fortemente influenciada pelo pioneirismo de Trinks\&Grossenbacher, cuja oficina de fundição foi fundada no início do século XX na cidade de Joinville. Maria Cristina Dias ${ }^{22}$, em artigo do Jornal ANoticia online publicou matéria sobre a trajetória do metalúrgico Otto Bennack, que possuía uma Metalúrgica que funcionava na rua Itajaí e fazia máquinas agrícolas, na primeira metade do século XX, empresa que fez parte do dia a dia da rua Itajaí, ou rua Itajahy (como antigamente chamava), como atestam as placas que ainda hoje estão no local. Tal Metalúrgica iniciou suas atividades como uma "pequena ferraria e se desenvolveu até se transformar em uma das maiores empresas da área de metalurgia da Joinville das primeiras décadas" do século XX.

${ }^{21}$ SENAI, DN, 2002, p. 19.

22 DIAS, Maria Cristina. Surge uma grande empresa. Jornal ANotícia. Disponível em: <http://www1.an.com.br/1998/jun/07/0cid.htm> 07 jun 1998, Acesso em: 24 maio 2012. 
A jornalista entrevistou o neto de Otto Bennack, o aposentado Nelson Jansen, que lhe contou "que o avô era o único filho do antigo representante do príncipe de Joinville, FredericBruestlein. Entretanto, ele não carregava o sobrenome do pai, que apesar de ter vindo da França com a companheira, e com ela ter vivido por toda a vida, nunca formalizou a união e nem reconheceu oficialmente o filho". Bruestlein presenteou ao filho uma ampla área de terra na rua dos fundos do palácio, onde morava. Foi nesse terreno, "entre a esquina das ruas Itajaí e 7 de setembro até o limite com o quintal da área dos príncipes e prosseguia na mesma direção do outro lado da rua, que o jovem Otto Bennack montou seu negócio e ganhou a vida". A metalúrgica chegou a ser uma das maiores do Sul do País, contudo no período entre guerras a empresa caiu em declínio, "neste período intensificou-se a perseguição aos que tinham origem germânica e bastava ter sobrenome alemão para entrar na "lista negra" do governo federal e se ver impedido de fazer negócios, principalmente com o exterior". E assim, a metalúrgica foi vendida para a "Superintendência das Empresas Incorporadas, um órgão federal, e continuou a funcionar, sendo vendida após a guerra para um grupo do Rio de Janeiro. Otto Bennack, porém, já idoso não resistiu e faleceu em seguida”.

Além da oficina de Trinks\&Grossenbacher, a metalúrgica de Otto Bennack foi, certamente, modelo para outras diversas que iniciaram seus próprios negócios com capital não-ervateiro, este era o negócio mais vantajoso na época, bem lembrado por Pavanello e Guedes ${ }^{23}$. "Apesar de Joinville situar-se distante do centro econômico

${ }^{23}$ Apesar de o município ter se desenvolvido comercialmente desde os primórdios de sua colonização, em meados do século XIX, e tal característica ter sido acentuada no início do século XX, sobretudo com a industrialização, comercialização e exportação de erva-mate, Joinville sempre foi mais popular por seu potencial industrial, chegando a ostentar o título de Manchester Catarinense. PAVANELLO, L.; GUEDES, S. Um novo olhar sobre o patrimônio comercial: os secos e molhados em Joinville. Rev História: Questões e Debates, Curitiba, n 59, pp. 241-261, jul/ dez 2013. Edit UFPR, p. 242. 
nacional, a diversificação e ampliação da estrutura produtiva local indicam certo dinamismo, sobretudo, dos segmentos da eletrometal-mecânica, em acompanhar o processo de industrialização brasileira"24.

Portanto, de acordo com as memórias inseridas no vídeo intitulado: Registro do desenvolvimento das ferramentarias de Joinville ${ }^{25}$ e pela narrativa da memória de Rudolf Hufen: a primeira ferramentaria, propriamente dita, que se tem notícia é a de propriedade do Sr. José Lenske, que realmente era ferramenteiro e realizava todo o processo de produção, contudo vale lembrar que o

Sr José Lenske era húngaro e era chefe de moldes na empresa Hansen Máquinas, (parte da antiga empresa Tigre) que após alguns anos foi trabalhar na empresa Polimold / Polimatic. (depoimento Rudolf Hufen).

Posteriormente surgiram ainda: Mecânica Garibaldi Ltda, do Sr. Eurico Schwoelk ${ }^{26}$, Ferramentaria Manchester, Ferramentaria Chiodini e Ferramentaria Kato. Essa memória é confirmada por alguns dos entrevistados.

Embora, WillandTiergarten ilustra de modo diverso ao que se está comentando, pois entende que a empresa joinvilense mais antiga ainda em funcionamento, na área de ferramentaria seria a BTOMEC ${ }^{27}$, fundada em 1985. O entrevistado se corrige, dizendo que

caso não fosse a BTOMEC, seria a Ferramentaria Garibaldi, que acabou fechando mais tarde. A própria Ferramentaria Chiodini também não mais existe.

${ }^{24}$ BAKKAR, Muhamad. op. cit. pp. 36-37.

25 SACCHELLI, Carlos M. Registro do desenvolvimento das ferramentarias de Joinville.Entrevistas Transcritas. Joinville: ed. Eugênio Siqueira, out 2009.

${ }^{26}$ Endereço da mecânica, na época: Avenida Santos Dumont, 2625, Joinville.

27 Endereço da Ferramentaria: BTOMEC Ferramentaria e Usinagem de Precisão. Rua Sorocaba, 91 - Floresta. 
No entanto, as memórias de Christian Dhilmann, diferentemente dos demais depoimentos, lembra que a empresa mais antiga, no que se refere às ferramentarias de moldes de plásticos, especificamente, seria a Tigre, e ainda relata que a empresa fabricava pentes de chifre de boi e depois de certo tempo passou a fabricar pentes de plástico. Mas, de acordo com o entrevistado não havia uma grande demanda na época e ainda conta que o senhor João Hansen Junior (fundador da empresa Tigre), em uma viagem ao exterior, foi apresentado às conexões metálicas e de plástico como uma alternativa na área de plástico.

Ele [João Hansen Junior] gostou da ideia e começou a implementar isso em Joinville, tanto que a Tigre começou a crescer [...] em projeção geométrica. (depoimento de Christian Dhilmann)

O entrevistado entende, contudo, que a empresa mais antiga, mas que já encerrou as suas atividades, de ferramentaria foi a Mecânica Garibaldi Ltda, do Sr. Eurico Schwoelk. Entendimento este que quando opera-se a memória, de acordo com $\mathrm{Candau}^{28}$, sobre algum acontecimento rememorado, este está sempre em relação estreita com o presente do narrador / entrevistado, ou seja, com seu tempo. É um vai-e-vem, entre a memória recente e a memória do passado.

Vale lembrar que estes ferramenteiros até aqui citados, primeiramente trabalhavam, em sua maioria dentro de grandes empresas, como a Hansen Máquinas, Tigre, etc, fazendo os moldes de ferramentaria e engrenagens de máquinas e que somente após a onda demissionária que ocorreu em meados da década de 1980, fez com que alguns deles abrissem suas próprias empresas, e outros mudassem de área ou permanecessem desempregados, como já explicado na Introdução.

28 CANDAU, Joël. op. cit., p. 101. 
Os primeiros funcionários e também os fundadores destas ferramentarias eram profissionais muito criativos, que aliado ao conhecimento de matemática e engenharia ajudaram na implantação e desenvolvimento das empresas. O depoimento de MJL, citado em livro sobre o profissional ferramenteiro, publicado pelo SENAI $^{29}$, reafirma que o ferramenteiro deve conhecer bem geometria e matemática, tem que conhecer bem maquinaria, tem que ter habilidades manuais, tem que conhecer processo de fabricação... Isso é imprescindível.

O Sr. Rudolf menciona que o trabalho de ferramenteiro na criação de moldes é "de profunda dedicação no desenho do molde, que demora dias, na maioria das vezes, meses no processo de criação. Exige conhecimento de desenho técnico. Depois, de criado o molde,a peça é produzida". Lembra que de posse do molde, a peça pode ser reproduzida " $n$ " vezes. Comenta que primeiramente fabricou anzóis, correntes de bicicleta, peças e acessórios para reposição de máquinas de tecelagem, armários de gelo para geladeira.

A criatividade destes técnicos especialistas na fabricação de moldes surgiu da necessidade em inovar, transformando literalmente ideias em projetos no papel. Ato este bastante preciso, delicado, do ponto de vista do engenho da criação, bem como original, considerando que cada molde corresponde a uma peça que será produzida futuramente, molde este vindo do intelecto humano planejado, a partir da necessidade humana, advindas da sua realidade social.

O surgimento dessas ferramentarias, além de outras tantas, decorreu da proibição da importação de máquinas vindas do estrangeiro, durante a ditadura militar, obrigando diversas grandes empresas a demitir seus trabalhadores, todavia os estimulando a abrir seus próprios negócios, terceirizando os serviços de ferramentarias que

29 Entrevista de Marcelo José de Lima, da empresa Plona, em Curitiba / Pr. In:SENAI, DN, 2002, p. 36. 
anteriormente era desenvolvido dentro da própria empresa. Exemplo disso ocorreu na Embraco, Consul, Cipla, Tupy e Tigre, empresas estas de grande porte e reconhecidas nacionalmente, o que confirmam as memórias dos entrevistados.

O entrevistado, WillandTiergarten, relata que a cidade de Joinville sempre foi considerada por possuir um pólo industrial muito forte, coadunando com o que foi dito. E que em sua maioria os ferramenteiros não eram moradores da cidade, porém sabendo da grande produtividade e empregos que aqui se dispunham, resolveram mudar-se para a maior cidade do Estado de Santa Catarina (em população), em busca de melhores condições de vida e consequentemente, uma melhor posição profissional.

Muitos dos ferramenteiros aprendiam sua profissão dentro da fábrica, a partir da experiência vivida no processo produtivo. Assim, relata o Sr. Schmalz que era muito difícil ir aprender em outras cidades maiores, então lembra que algumas empresas "implantaram um centro de treinamento que ensinava inclusive os filhos dos funcionários". Também, o Sr. Ronaldo menciona que foi a melhor solução encontrada para o momento, pois as escolas de ofício não existiam em Joinville na época. Lembra que, antes desses centros de treinamento para ferramenteiro, os profissionais aprendiam um com outro, ou seja, "um aprendiz ficava junto com um ferramenteiro experiente na fábrica e ia aprendendo o ofício com quem sabia e tinha também aprendido na prática do dia a dia na indústria”.

As ferramentariassão parte integrante do setor metalomecânico. Assim, as memórias revelam que o processo de downsize desverticalização, dentro das grandes empresas foi um dos grandes fatores do surgimento da maior parte das novas ferramentarias até então inexistentes. Processo este que o entrevistado, Sr. WillandTiergarten, relembra dizendo que 
a Embraco eliminou pessoal, a Hansen Máquinas [hoje Tigre] fechou cem por cento, eram trezentos a quatrocentos funcionários, ela acabou fechando de uma hora para a outra. A Cipla acabou diminuindo a ferramentaria, também a Embraco acabou diminuindo, bem como a Multibrás. Enfim, a Tupy pôs fim à ferramentaria. Ou seja, essa explosão (processo de downsize) de fechar as ferramentarias, acabou sobrando muita mão de obra, e não tinha tantas empresas, nem tantos empregos.

\section{O Sr. Willard Tiergarten demonstra através da narrativa de suas lembranças que ao mesmo tempo que o processo de downsize foi decisivo para o início das "novas" ferramentarias, foi um grande gerador de desemprego para a região.}

\section{E ainda, da mesma forma Carlos Alberto Lessa lembra que:}

A Tigre e a Consul tinham uma boa ferramentaria. A Embraco e a Tupy, todas elas desverticalizaram. Por que no começo dos anos noventa surgiu no mundo uma revolução chamada reengenharia ${ }^{30}$. Algumas empresas entenderam a reengenharia de forma inteligente, outras nem tanto. Todas as empresas que tinham ferramentaria, as desativaram e foi aí que surgiram as pequenas empresas. Houve um incentivo das próprias grandes

30 "A Reengenharia, conceito introduzido por James Champy e Michael Hammer através do best-seller "Reenginneringthe Corporation" publicado em 1993, consiste em repensar e redesenhar radicalmente as práticas e processos nucleares da organização tais como o serviço ao cliente, o desenvolvimento de novos produtos, a cultura organizacional, a resposta às encomendas, entre outras, afim de aumentar a produtividade através da redução de custos e do aumento do grau de satisfação do cliente. Ao contrário da TQM (Total Quality Management), a Reengenharia não procura introduzir melhorias em processos já existentes mas sim a eliminação e total reinvenção das regras e processos já ultrapassados bem como de todos os pressupostos fundamentais que lhe servem de base. Daqui resulta outra diferença chave da Reengenharia em relação à TQM: enquanto a TQM tem um elevado grau de participação dos subordinados e visa a obtenção de resultados num espaço de tempo alargado, a reengenharia parte de cima para baixo (dos gestores para os subordinados) e visa obter resultados num curto espaço de tempo". NUNES, Paulo.O conceito da Reengenharia. Susana Saraiva (trad.)ago, 2008. Disponível em: $<$ http:// www.knoow.net/cienceconempr/gestao/reengenharia.htm> Acesso em 22 nov 2011. 
empresas de fazer com que seus trabalhadores, que desenvolviam suas tarefas nas ferramentarias pudessem montar seus próprios negócios.

A partir deste novo boom industrial, na cidade de Joinville surgiram estas diversas empresas de ferramentarias, ainda que na época pequenas. Este é o grande motivo da cidade ter um grande destaque no setor, sendo referência nacional no pólo de fundição. Ainda Ademar Hessen, neste mesmo sentido afirma que

muita gente que se aposentou junto a empresa Tigre, chegou a comprar um "torno"31 financiado e trabalhava, não mais para a Tigre, mas para outras empresas.

\section{Sobre os primeiros moldes, Ademar Hessen comenta que}

não havia desenho, era o próprio ferramenteiro que sentava na sua "mesinha", pegava os papelões, cortava no tamanho e desenhava. Assim vai ser o molde (um exemplo): quatro cavidades, ou duas cavidades. "Bem no facão mesmo!'E dali ia para a fresa universal (fig . 1), ou para uma furadeira de coluna, que eram ferramentas mais precisas. Tudo era muito rudimentar!

31 Torno mecânico é uma máquina-ferramenta que permite usinar peças de forma geométrica de revolução, permite a usinagem de variados componentes mecânicos: possibilita a transformação do material em estado bruto, em peças que podem ter seções circulares, e quaisquer combinações destas seções.O torno mecânico é a máquina que está na base da ciência metalúrgica, e é considerada a máquina ferramenta mais antiga e importante ainda em uso. Disponível em: <www.wikipedia. com.br> Acesso em: 12 maio 2012. 
Figura 1: Fresa universal e Furadeira de coluna, 2007.
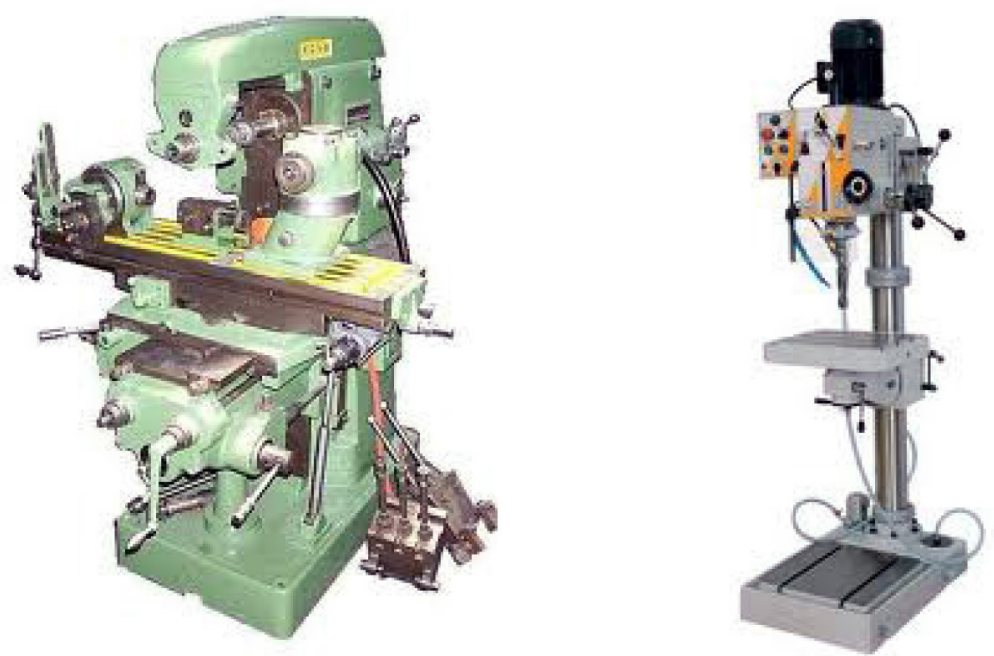

Fonte: Disponivel em: <http://www.cgimoveis.com.br/tecnologia/maquinasgenericas/maquinas2008-10-30.9960916137> Acesso em: 10 nov 2011. web.

Apresentam-se na figura 1 um modelo de fresa universal e uma furadeira de coluna, respectivamente, para se ter uma ideia do sistema na qual estes criadores trabalhavam.

\section{Considerações}

A narrativa das memórias aqui relatada de como as primeiras ferramentarias de Joinville foram criadas, abre caminho para uma discussão, mais aprofundada futura, sobre o patrimônio industrial da cidade. Algo que não se pode perder. Criar um molde "no facão" como descreveu o Sr. Ademar Hessen, que trabalhou na Tigre, Akros e Fred Jung, comparando com o maquinário hoje existente é um resgate do passado sem precedentes. 
A criatividade, paciência e persistência destes trabalhadores surpreende a qualquer ouvinte. O início dos trabalhos destes ferramenteiros foi pioneiro, pois o desenvolvimento de um molde que futuramente cria um produto, há a necessidade de todo um conhecimento industrial bastante arrojado para a época, quando os primeiros começaram a surgir. Após o acerte do molde, diversos produtos, a partir dele são criados, todos idênticos e normalmente perfeitos, não havendo mais a necessidade da criação unitária, peça por peça, como faziam as corporações de ofícios há muitas décadas.

A profissão de ferramenteiro sempre possuiu certas virtudes peculiares, como a criatividade, inovação e organização. A criatividade vê-se pela capacidade de invenção e imaginação de moldes, produtos, enfim, meios de se criar algo a partir da arte dos desenhos. A inovação está completamente unida à criatividade, porém esta capacidade é complementar a ela, pois inovando, tem-se as constantes transformações tanto de produtos finais, como também a forma de produção destes produtos. E ainda sobre a organização, os ferramenteiros são muito organizados, a tal ponto de criar um núcleo setorial, dentro da Associação Empresarial da cidade de Joinville, que trate das dificuldades e conquistas de um setor extremamente concorrente.

Todas as narrativas das memórias dos ferramenteiros de Joinville nos fazem acreditar que apesar da crise econômica que ocorreu durante as décadas de 1980 e 1990, as empresas desse setore os empresários conseguiram se manter em funcionamento. De modo que "não pode haver construção de uma memória coletiva se as memórias individuais não se abrem umas às outras visando objetivos comuns, tendo um mesmo horizonte de ação"32. A cultura sobre o potencial industrial que se desenvolveu em Joinville e que ainda hoje percebe-se no cotidiano dos cidadãos já se trata de uma memória coletiva, lembrada, sentida e rememorada todos os dias pela cidade pulsante.

${ }^{32}$ CANDAU, Joël. op. cit., p. 48. 
Afinal, a esta "imagem construída não só pela historiografia local, como também pelo empresariado e pelo poder público", como se pode verificar por meio dos autores citados e também pelas memórias dos entrevistados, é um discurso que ultrapassa "a fala das lideranças e que ao longo da construção de Joinville encontrou ressonância na população" ${ }^{33}$.

A cultura industrial de Joinville, ou seja, este patrimônio imaterial é algo que não mudará tão cedo, pois este olhar de cidade trabalhadora e preocupada com seu futuro passa de geração para geração. A perda desta "memória é, portanto, uma perda de identidade" 34 da cidade, o que não ocorrerá tão cedo. Obviamente que seria a perda de uma de suas identidades, considerando que a cidade possui diversas e múltiplas facetas identitárias.

A indústria, os seus espaços, ainda que hoje vazios, os seus trabalhadores, ainda que alguns já aposentados, o espírito empreendedor que reina neste ambiente, todos estes agentes fazem parte do patrimônio industrial material e imaterial (perspectivas inseparáveis) das cidades. Joinville pela sua trajetória histórica da vinda dos imigrantes e depois com uma nova vinda de "migrantes", tem hoje uma cultura direcionada ao seu potencial industrial, às suas riquezas, mas que também vem se modificando, abrindo portas para outras áreas da cultura, como o teatro, música, arte, o próprio lazer sem compromisso. Contudo o espírito do trabalho na indústria ainda está muito presente, enraizado na identidade das pessoas e em suas memórias.

A decisão de muitos de nossos antepassados de vir morar na cidade de Joinville foi tomada pela simples razão de melhorar de vida, através de melhores salários, ou quem sabe por haver mais opções para abrir um novo negócio. Ninguém sabe as reais intenções de

33 GUEDES, Sandra Paschoal Leite de Camargo (org).Histórias de (i)migrantes: o cotidiano de uma cidade. Joinville: Univille, 2005. p. 194.

${ }^{34}$ CANDAU, Joël. op. cit., p. 59. 
cada um... são muitas... Mas o que não se pode negar é a identidade cultural voltada para o trabalho e para o desenvolvimento para todos. Para todos? Bom, se é para todos não se sabe, o que aqui não mais há possibilidade de se discorrer.

Enviado em 12 de outubro de 2014

Aprovado em 23 de setembro de 2015 